\title{
Atuação brasileira na agenda regional de segurança e defesa: possibilidades de autonomia diante das mudanças sistêmicas
}

Brazil's role in the regional agenda for security and defense: autonomy possibilities on the systemic changes

Naiane Inez Cossul ${ }^{1}$

\section{Resumo:}

O artigo objetiva discutir a atuação brasileira na construção da agenda regional de segurança e defesa, ressaltando que as mudanças sistêmicas ocorridas no pós-Guerra Fria e no pós-11 de Setembro permitiram espaços de autonomia regionais e um maior protagonismo brasileiro.

Palavras-chave: atuação brasileira; agenda regional de segurança e defesa; mudanças sistêmicas.

\section{Abstract:}

The article discusses the Brazilian role in the construction of the regional agenda for security and defense, pointing out that the systemic changes in the post-Cold War and postSeptember 11 allow regional spaces of autonomy and a greater Brazilian leadership.

Keywords: Brazilian practice; Regional agenda for security and defense; Systemic changes.

\section{INTRODUÇÃO}

Durante os últimos anos, a América do Sul tem adquirido um inédito caráter de importância para o Brasil. Esse olhar estratégico para a região foi motivado por diversas mudanças do sistema internacional, que culminaram na adoção de uma nova matriz de política externa, a qual buscou, entre outras coisas, aprofundar a integração regional. A novidade desse viés integracionista está na clara delimitação geográfica que congrega todos os países sul-americanos e avança, para além das questões comerciais e econômicas, nos assuntos de segurança e defesa. A União das Nações Sul-Americanas

\footnotetext{
${ }^{1}$ Doutoranda do Programa de Pós-Graduação em Estudos Estratégicos Internacionais da Universidade Federal do Rio Grande do Sul - PPGEEI/UFRGS, Porto Alegre, Brasil.
} 
(Unasul) e o Conselho de Defesa Sul-Americano (CDS) são iniciativas brasileiras e são fundamentais para o processo de inserção internacional do Brasil.

Desse modo, o artigo objetiva discutir a atuação brasileira na construção da agenda regional de segurança e defesa, ressaltando que as mudanças sistêmicas ocorridas no pós-Guerra Fria e no pós-11 de Setembro permitiram a criação de espaços de autonomia regionais e um maior protagonismo brasileiro.

Para a consecução desse objetivo, abordam-se, na primeira seção, as mudanças sistêmicas referentes ao surgimento de novos polos de poder com o fim do conflito bipolar e à substituição da agenda estadunidense da guerra às drogas pela guerra ao terror. Na segunda seção, tem espaço a análise referente à evolução da agenda de segurança e defesa do Brasil para a América do Sul, que passou a ter um caráter mais assertivo nos anos 2000, bem como a evolução da percepção do caráter estratégico e geopolítico da América do Sul para a inserção brasileira. Esses espaços de autonomia e de iniciativas brasileiras foram preponderantes para o surgimento da Unasul e do seu Conselho de Defesa Sul-Americano.

Por fim, a terceira seção aponta os limitantes dessa autonomia, os constrangimentos e as dificuldades em construir consensos regionais. Adotou-se uma pesquisa exploratório-descritiva na qual foram observados os elementos de mudanças no sistema internacional e no viés regional, sob o olhar do Brasil. A análise sobre o tema foi feita por meio de revisão bibliográfica e documental.

\section{MUDANÇAS SISTÊMICAS E A CRIAÇÃO DE ESPAÇOS DE AUTONOMIA}

O cenário internacional do período pós-Guerra Fria é marcado por "profundas transformações, as quais redefiniram não apenas os esquemas de distribuição de poder, mas também a natureza dos vínculos estabelecidos entre os atores do sistema, os seus padrões de atuação e as suas formas de composição e articulação" (OLIVEIRA; LESSA, 2006, p. 1).

O período marcado pela Guerra Fria manteve tanto as questões de política externa quanto as de segurança internacional restritas ao conflito bipolar. A política externa dos países incorporava os pressupostos da Guerra Fria, aliados às áreas de influência por parte dos Estados Unidos e da União Soviética, enquanto a segurança 
internacional estava centrada no aspecto militar-estratégico do Estado. As transformações ocorridas no final desse período têm importância destacada para as relações internacionais. Como afirma Tanno (2003, p. 47), "os eventos históricos tendem a engendrar desenvolvimentos da teoria" e pode-se dizer que, além de teorias, mudanças ditas sistêmicas.

Nesse sentido, Gilpin (1981, p. 39-40, tradução nossa) elenca três possibilidades de mudanças relevantes nos sistemas. A primeira e mais fundamental é a mudança do sistema, "uma mudança na natureza dos atores ou nas diversas entidades que compõem um sistema internacional". A segunda é a mudança sistêmica, "uma mudança na forma de controle ou governança de um sistema internacional", ou seja, a distribuição de poder. 0 terceiro tipo de mudança é a de interação, "uma alteração na forma das interações normais ou processos entre as entidades em um sistema internacional contínuo".

É possível afirmar, portanto, que o final da Guerra Fria estabeleceu uma mudança sistêmica que está em curso até os dias atuais. A distribuição de poder em dois polos deu lugar à unipolaridade dos Estados Unidos² e, nos últimos anos, a ideia de um mundo multipolar tem ganhado adeptos 3 . Segundo Maria Regina Soares de Lima (1996), "por qualquer definição canônica das relações internacionais, o fim da Guerra Fria foi uma mudança sistêmica (...)".

Para Ikenberry (2011), o fim da Guerra Fria foi um evento histórico-mundial que conservou e deu continuidade à consolidação da ordem pós-guerra liderada pelos Estados Unidos. Entretanto, as próprias mudanças do período advindas dessa ordem liberal corroeram a legitimidade da liderança, principalmente após os atentados de 11 de setembro, cujas diretrizes tendiam para uma liderança com características imperialistas, o que gerou contestação no sistema internacional.

\footnotetext{
2 Segundo Maria Regina Soares de Lima (1996), "a tese da constituição de um sistema unipolar sob a liderança dos EUA foi talvez aquela mais difundida após a queda do Muro de Berlim, não apenas por especialistas, mas também pelos meios de comunicação e, inclusive, por estrategistas da política externa norte-americana do governo Bush adeptos da adoção de uma nova concepção estratégica que, com o colapso da União Soviética, preservasse a situação unipolar que o fim da bipolaridade presenteara os EUA".

${ }^{3}$ Segundo Ikenberry (2011), a distribuição de poder, a erosão das normas de soberania e o novo escopo e caráter da interdependência enfraqueceram a liderança estadunidense. Exemplos disso são as novas formas de violência e insegurança oriundas do pós-Guerra Fria, difusas e descentralizadas, com a emergência de novos atores e conflitos intraestatais, as crises econômicas recentes e China e Índia como polos de poder não ocidentais, além da participação ativa dos grupos de países em desenvolvimento, que buscam voz ativa nos fóruns mundiais e compartilhamento da governança mundial.
} 
Nesse sentido, essa mudança sistêmica engendra alterações na natureza dos vínculos entre os atores do sistema, os seus padrões de atuação e as suas formas de composição e articulação. Permeados pela globalização, os Estados passaram a dividir a agenda de questões estratégico-militares, que não deixaram de fazer parte da agenda internacional, com novos temas - que se configuram com natureza e intensidade distintas a cada Estado, desafiando com fluidez as fronteiras estatais e com o acréscimo de novos e distintos atores - transpondo fatores domésticos à ordem internacional.

O Brasil não ficou avesso às mudanças e, para o diplomata brasileiro Paulo Roberto de Almeida (2009), a globalização ampliada pelo fim da Guerra Fria “(...) estimulou os esforços do Brasil em prol da integração regional e com vistas à inserção da economia brasileira nos grandes fluxos globais de comércio, de investimentos, de tecnologia e em outros circuitos relevantes da interdependência mundial".

Os movimentos de regionalização foram reforçados no pós-Guerra Fria "como um movimento de defesa às mudanças internacionais contemporâneas" (LIMA; COUTINHO, 2005)4 . Nesse sentido, “(...) a importância do regionalismo no pós-Guerra Fria permitiu um maior espaço de autonomia para que as próprias regiões passassem a se ocupar de suas agendas de segurança. O papel do Brasil nesse contexto assume relevância destacada" (PAGLIARI, 2009, p. 13). Para Silva (2015, p. 177), na política externa brasileira, "ocorreu uma nova linha de atuação, baseada em uma nova concepção multilateral, assentada em uma interpretação da difusão de poder no sistema internacional, com tendências multipolares".

Dessa forma, a mudança na forma de controle ou governança de um sistema internacional, definição de mudança sistêmica trazida por Gilpin (1981), pode ser observada, depois do período de unipolaridade estadunidense, como um compartilhamento de poder dos Estados Unidos com as potências regionais. Pecequilo (2008, p. 144) reitera essa ideia:

(...) o ordenamento do sistema passou a ser visto de um ponto de vista realista, transitando da uni à multipolaridade. Ainda que detenham poder incontestável no campo militar, os EUA tendem a compartilhá-lo nas demais esferas devido à intensificação dos processos de interdependência e transnacionalização por

\footnotetext{
${ }^{4} \mathrm{O}$ sistema internacional passou por ondas de regionalização. Esta a que se refere aqui é o chamado novo regionalismo dos anos 90. "A política e a economia passam, então, a se organizar segundo esquemas regionais, porque dessa maneira permitem uma resposta mais eficaz à competição global" (LIMA; COUTINHO, 2005).
} 
eles mesmos capitaneados. A diversificação dos polos de poder, incluindo potências desenvolvidas e emergentes, caracteriza este momento: China, Índia, Rússia, União Europeia, Japão, Brasil e África do Sul são alguns destes agentes.

Demonstra-se, com os trechos elencados, que o período pós-Guerra Fria, que, dentre tantas características, destacou-se pelo regionalismo e compartilhamento de poder, promoveu mudanças sensíveis nas relações internacionais. Do mesmo modo, o 11 de setembro de 2001, dia em que os Estados Unidos sofreram um atentado terrorista às Torres Gêmeas, marcou sobremaneira o campo de estudo. Dois marcos históricos, portanto, que engendraram substanciais mudanças sistêmicas.

Em relação ao 11 de Setembro, pode-se afirmar que houve um deslocamento da política externa norte-americana da guerra às drogas para a guerra do terror. A guerra às drogas remonta ao período da administração Nixon, que, a partir de 1971, colocou as drogas como inimigo número um dos Estados Unidos. A América do Sul passou a sentir os efeitos diretos dessa política a partir dos anos 2000, com a adoção do Plano Colômbia. A política adotada foi a repressão como estratégia de contenção da oferta, com um forte componente militar e policial, através da preferência de combate à oferta e não ao consumo, como forma de transferir os custos sociais aos países produtores (PAGLIARI, 2009).

A guerra ao terror teve início após os atentados terroristas de 11 de setembro de 2001 e também ficou conhecida como Doutrina Bush. Em 2002, a Estratégia de Segurança Nacional dos Estados Unidos (NSS-2002) reuniu elementos dessa nova política externa. Justificou-se assim, unilateralmente, a invasão do Afeganistão e do Iraque e a construção de um discurso para tratar como terroristas os países do chamado "eixo do mal", que abrigam ou dão apoio aos grupos terroristas, bem como a política de guerra preventiva. A centralidade desse tema na agenda de segurança norte-americana produz "efeitos sobre dinâmicas econômicas e políticas internacionais" (SOUZA; MORAES, 2014, p. 13) e nesse sentido a guerra ao terror "implicou maior apoio doméstico nos Estados Unidos ao fornecimento de cooperação militar para países que enfrentavam o problema do terrorismo" (SOUZA; MORAES, 2014, p. 22).

Assim, o fato de a guerra ao terror passar a permear o espaço na agenda americana que era dedicado à guerra às drogas pode ser considerado uma inflexão, 
ainda que relativa e processual, na política externa norte-americana, aliada às mudanças no sistema internacional e à distribuição de poder, o que permitiu o surgimento de espaços de autonomia sul-americanos. Embora, como ressaltam Buzan e Waever (2003, p. 328), com o impacto do 11 de setembro de 2001, incorreu-se o risco de uma mudança de conceituação da Colômbia como parte da guerra ao terrorismo, saindo de uma posição estritamente hemisférica/regional, no combate às drogas, para uma justificativa global, da guerra contra o terrorismo.

Assim, em relação à América do Sul, "a mudança da relação com os EUA é parcialmente um produto da mudança de prioridades dos EUA" (BUZAN; WAEVER, 2003, p. 334, tradução nossa), ao passo que Washington passou a priorizar outras regiões. Para Fuccile e Rezende (2013, p. 82), “os Estados Unidos acabam servindo como pretexto para a cooperação dos países sul-americanos".

Essa relação de presença dos Estados Unidos na América do Sul pode ser descrita também por meio do fenômeno chamado overlay ou sobreposição, trazido por Buzan e Waever (2003, p. 63), no qual a região apresenta um Estado que domina as dinâmicas de segurança, projetando a sobreposição das suas demandas securitárias sobre as outras dinâmicas de segurança daquela região - quando uma potência externa à região define a segurança regional. Esse fenômeno descreve a relação dos Estados Unidos com a América do Sul, mas ela, paulatinamente, cede espaço para mecanismos de autonomia próprios à região, devido aos argumentos trazidos até aqui.

Nesse sentido, destaca-se também o rebalanceamento das forças norteamericanas para a região da Ásia-Pacífico (Asia-Pacific Rebalance). 0 sítio do Departamento de Defesa (DoD) diz que os "líderes de defesa mantêm o foco em esforços para fortalecer relacionamentos e modernizar alianças norte-americanas na região da Ásia-Pacífico como uma prioridade para os interesses de segurança do século 21 e sustentar a liderança global dos EUA" (DoD, Top Issues, Asia-Pacific Rebalance, 2015, tradução e grifo nossos).

Pode-se afirmar, então, que os movimentos regionalistas do pós-Guerra Fria, somados à mudança da política externa norte-americana da guerra às drogas para a guerra ao terror - duas mudanças às quais se atribuiu a característica de sistêmicas -, permitiram que a região sul-americana criasse espaços de autonomia. Ressalta-se ainda que o Brasil gradativamente foi se aproximando da América do Sul e, apenas 
recentemente, passou a construir as bases para que esta se tornasse o eixo principal de orientação da sua política externa. Couto (2009) salienta que o país já teria sido americano, latino-americano e, desde 1990, se tornado um país sul-americano. E podese acrescentar que, desde os anos 2000, tem buscado criar sua própria agenda de segurança e defesa para a América do Sul.

\section{EVOLUÇÃO DA AGENDA DE SEGURANÇA E DEFESA DO BRASIL PARA A AMÉRICA DO SUL}

A busca pela autonomia sempre pautou a política externa brasileira. Todavia, essa busca também está condicionada às limitações impostas pelo sistema internacional. Por isso, as mudanças sistêmicas são importantes para o entendimento do processo de criação de espaços de autonomia para a construção de uma agenda regional de segurança e defesa.

Pinheiro (2000) identificou que as principais matrizes teóricas da política externa brasileira tiveram relação com o chamado "desejo de autonomia". Essa busca pela autonomia foi o principal traço de continuidade, sendo reinterpretada à luz dos interesses de cada momento da política externa. Para Russell e Tokatlian (2003, p. 162), autonomia é uma condição de Estado que lhe possibilita articular e alcançar objetivos políticos de forma independente, variando de total dependência ou completa autonomia - depende das capacidades duras e brandas dos Estados e das circunstâncias externas que se apresentam. Do mesmo modo, os autores acrescentam que a noção de autonomia externa é a habilidade do Estado, entendida como capacidade e disposição, para tomar decisões baseadas em necessidades e objetivos próprios sem interferência e constrangimentos externos.

Desse conceito destaca-se a ideia de capacidade e disposição. Saraiva (2014) afirma que as dinâmicas da política externa de um país estão associadas, geralmente, ao ativismo de atores políticos domésticos, bem como dependem de fatores conjunturais externos. Nos últimos anos, o Brasil aliou essas duas ideias e contou com um contexto doméstico e internacional favorável para a instrumentalização dessa autonomia. 
Com as transformações internacionais do pós-Guerra Fria, o aspecto regional ganhou importância como um dos eixos articuladores da inserção externa do país. ${ }^{5}$ Do contexto doméstico, ressalta-se o final do governo Fernando Henrique Cardoso (FHC) e o governo de Luiz Inácio Lula da Silva (Lula), que mostraram disposição para trazer de forma preeminente a América do Sul para o discurso e denotaram crescente importância do entorno regional para a política externa brasileira, enquanto, no contexto internacional, as mudanças sistêmicas, elencadas na primeira seção, mantiveram a atuação direta dos Estados Unidos afastada, de algum modo, da região.

É a partir do segundo mandato de FHC que "a América do Sul ganha um conteúdo bastante definido" (SANTOS, 2004, p. 123). Em 2000, ocorreu também a primeira Cúpula Sul-Americana, primeira vez em que todos os chefes de Estado do continente se reuniram, a fim de discutir um projeto de integração da América do Sul. A participação dos 12 presidentes da América do Sul significou o início de três reuniões celebradas entre 2000 e 2004 para acordar políticas de integração regional e que deram origem à Comunidade Sul-Americana de Nações (Casa).

A Casa, portanto, foi criada na terceira cúpula, em Cusco, no Peru, com o intuito de avançar nos anseios de seus povos para o objetivo de integração, unidade e construção de um futuro comum (DECLARAÇÃO..., 2004). A partir da criação da Casa, em 2004, as reuniões passaram a ser anuais e, em 2008, em Brasília, mediante aprovação do tratado constitutivo, a Comunidade Sul-Americana de Nações passou a ser designada oficialmente como União de Nações Sul-Americanas (Unasul).

A aproximação entre todos os presidentes sul-americanos, além de ser um exemplo da autonomia regional, advém da necessidade de criação de um espaço institucional para a utilização dessa autonomia, no qual possam ser discutidos problemas concernentes à região, sem a interferência de um país extrarregional. Em 2003, no primeiro discurso do então presidente Lula na ONU, ele enfatizou:

O Brasil tem se esforçado para praticar com coerência os princípios que defende. 0 novo relacionamento que estamos estabelecendo com os vizinhos do continente sul-americano baseia-se no respeito mútuo, na amizade e na

\footnotetext{
${ }^{5}$ É nesse período recente que a região passa a ser instrumentalizada pela política externa brasileira. Todavia, como ressalta Moniz Bandeira, a partir da metade do século XX, o Brasil buscou estreitar laços com os países da América do Sul - fora do eixo da Bacia do Prata -, em especial com aqueles com os quais o país não possuía relações tão próximas, como as repúblicas do Pacífico e da região amazônica (BANDEIRA, 2006).
} 
cooperação. Estamos indo além das circunstâncias históricas e geográficas que compartilhamos, para criar um inédito sentimento de parentesco e de parceria (SEIXAS CORRÊA, 2007, p. 705).

Assim, a integração sul-americana, que já estava entre as prioridades do governo Fernando Henrique Cardoso, ganhou a condição prioritária no governo Lula, “com mudanças de ênfase, intensidade ${ }^{6}$, empenho e conteúdo" (SANTOS, 2004, p. 147). A América do Sul ganhou uma visão estratégica "de transformação da ordem internacional e de busca de uma melhor inserção internacional para o Brasil, para seus vizinhos (...) (SANTOS, 2004, p. 147)7

Assim, com um ambiente institucional criado, foi possível iniciar as discussões sobre uma agenda regional de segurança e defesa. A concepção do Conselho de Defesa Sul-Americano (CDS), em 2008, no âmbito da Unasul, é um ponto de inflexão "à clássica ideia de segurança coletiva herdada da Guerra Fria - sob a liderança norte-americana (...)" (FUCILLE, 2014). Nesse sentido,

A crescente erosão da legitimidade do modelo de segurança coletiva do período anterior, confirmada por exemplos como a pouca efetividade do Tratado Interamericano de Assistência Recíproca (Tiar), da Junta Interamericana de Defesa (JID) e até da própria Organização dos Estados Americanos (OEA), combinada a um crescente desengajamento dos EUA na região, bem como a novas prioridades por parte do Departamento de Estado estadunidense pós-11 de setembro de 2001, acabaram por consolidar um imaginário na América do Sul de espaço geográfico possível e passível de desenvolver políticas mais independentes, advindas de uma maior margem de autonomia (FUCILLE, 2014, grifo nosso).

O CDS, gestado pelo Brasil, coloca-se como um canal de consenso e maior adensamento das relações dos países da região no que concerne às ameaças comuns à

\footnotetext{
${ }^{6}$ Segundo Santos (2004, p. 147), a expressão "América do Sul" passou a integrar praticamente todos os discursos, entrevistas e textos de Lula. Nos oitos anos do governo FHC, há 85 textos presidenciais (dos quais apenas 12 do primeiro mandato) em que essa expressão aparece. Em contraste, nos dois primeiros anos de sua gestão, Lula mencionou a "América do Sul" em 106 textos. Além disso, em cinco meses de governo Lula, sete presidentes sul-americanos vieram ao Brasil, algo que nunca ocorrera antes (Idem).

${ }^{7}$ Ressalta-se que, durante a década de 2000, as iniciativas de regionalismo tomaram proporções inéditas, como a citada criação da Comunidade Sul-Americana de Nações (Casa), a criação da Iniciativa para a Integração da Infraestrutura Regional Sul-Americana (IIRSA), do Fundo para a Convergência Estrutural do Mercosul (Focem), a União de Nações Sul Americanas (Unasul) e seu Conselho de Defesa Sul-Americano (CDS) e o Conselho Sul-Americano de Infraestrutura e Planejamento (Cosiplan).
} 
estabilidade da região: as chamadas novas ameaças, advindas de atores não estatais, como o tráfico de drogas e de armas e uma diversidade de ilícitos que compõem o crime organizado transnacional, bem como a existência de problemas fronteiriços entre Chile/Bolívia, Chile/Peru, Equador/Peru e Colômbia/Venezuela. Além disso, a tradicional militarização da agenda de segurança norte-americana para a região - com a presença do Comando do Sul (SOUTHCOM), o Plano Colômbia, com o envio de tropas e equipamentos militares, e a reativação da IV Frota Naval, em 2008 - também é um indicativo da importância do CDS. Para Battaglino (2009, p. 80), o CDS é a manifestação institucional da busca de liderança do Brasil na América do Sul.

Villa e Viana (2010) argumentam que, durante o governo Lula, as questões de segurança passaram de uma perspectiva reativa para assertiva. Enquanto, no primeiro mandato, houve uma ênfase em reagir às propostas apresentadas pelos Estados Unidos e pela Organização dos Estados Americanos (OEA), no segundo já ocorreu um papel bastante ativo: o envio de tropas brasileiras para a missão de estabilização no Haiti (Minustah), as negociações com as Forças Armadas Revolucionárias da Colômbia (Farc) para a libertação de reféns, a mediação na polêmica sobre energia nuclear envolvendo o Irã - incorporando, assim, questões globais. Essas iniciativas, segundo os autores, podem ser interpretadas como uma tentativa de reconhecimento internacional da capacidade do Brasil para construir diálogos sobre temas da agenda de segurança mundial e avançar em sua busca de um assento permanente no Conselho de Segurança da ONU.

Assim, "até o primeiro governo Lula, o Brasil não tem uma política de segurança em nível regional. Devido a esse 'vácuo' deixado pelo Brasil, a iniciativa em relação às questões de segurança na América do Sul tem sido tradicionalmente feita pelos Estados Unidos" (VILLA; VIANA, 2010, p. 91-92, tradução nossa).

A partir dessa proatividade do governo Lula para as questões securitárias no âmbito regional e das mudanças sistêmicas que culminaram no apoio dos EUA a um maior protagonismo brasileiro nas questões de segurança, observa-se que a agenda de segurança e defesa sul-americana foi sendo construída. Na Declaração de Política de Defesa do Hemisfério Ocidental (Western Hemisphere Defense Policy Statement), de 2012, consta que, devido ao rebalanceamento, os EUA procuram parcerias para dividir os custos e as responsabilidades para garantir a paz e a segurança, inclusive nas 
Américas. Assim, “(...) estamos incentivando a cooperação regional para melhorar a segurança e a estabilidade na América do Sul, acolhendo os esforços do Brasil e parceiros, (...) como o Conselho de Defesa Sul-Americano, que ajudam a construir interdependência e a integrar ainda mais as forças de parceiros (DoD, 2012, p. 2, tradução nossa).

Os elementos citados permitem fazer um paralelo com a fase, elencada por Pecequilo (2013), de "diálogo estratégico" entre Brasil e Estados Unidos, em que os "ganhos de autonomia nacional haviam qualificado o Brasil a ser encarado pelos EUA como parceiro global [...]. Essa qualidade elevada resulta das mudanças da presidência Bush no segundo mandato e do reforço da autonomia brasileira" (PECEQUILO, 2013. p. 80-81). Essa fase foi precedida por um período que a autora chama de "autonomia", no qual o relacionamento entre Brasil e EUA se manteve sem grandes conquistas ou rupturas. A ausência de avanços nas negociações da Alca e o esvaziamento da agenda norte-americana para a América do Sul devido à acentuada agenda neoconservadora da política externa de Bush, focada na Eurásia, foram fatores importantes para a inércia das relações bilaterais ${ }^{8}$.

Diante dos cenários apontados, o CDS surgiu com os objetivos de consolidar a América do Sul como uma zona de paz, construir uma identidade sul-americana em matéria de defesa e gerar consensos para fortalecer a cooperação regional no âmbito da defesa (Unasul, 2015). Para Granato (2014, p. 87), com a formação da Unasul, levou-se a cabo uma das principais metas da política externa do Brasil: "a criação de um novo espaço de concertação política, em que a América do Sul demonstre sua grandiosidade não somente no plano físico ou geográfico, mas, também, no plano diplomático das negociações internacionais". Nesse sentido, para o autor, a Unasul constitui uma das mais fortes expressões da reformulação da integração sul-americana. Acrescenta-se, todavia, que há limitantes e constrangimentos.

\section{UM BALANÇO DA AUTONOMIA: LIMITANTES E CONSTRANGIMENTOS}

\footnotetext{
${ }^{8}$ A autora traça as relações entre o Brasil e os Estados Unidos a partir de uma análise das relações bilaterais entre 1990 e 2011. Divide esse período em quatro fases: "alinhamento" (1990-1998), "autonomia" (1999-2004), "diálogo estratégico" (2005-2010) e "Brasil global" (2011) (PECEQUILO, 2013).
} 
O Brasil aproveitou o espaço dado pelas mudanças sistêmicas para avançar em questões sensíveis e, até então, inéditas - que dialogam com todos os países sulamericanos. As questões de segurança dos países sul-americanos passam a ter uma resposta multilateral, enquanto a abordagem bilateral caracterizara os tradicionais diálogos na região. Todavia, "a capacidade do Brasil, e dos demais países da América do Sul, de contrapor-se à agenda norte-americana é, por óbvio, limitada" (SVARTMAN, 2014, p. 54).

Para Silva (2014, p. 67-68), a política externa brasileira na primeira década do novo milênio, período delineado na seção anterior, que compreende o final do governo FHC em diante, se constituiu sobre uma nova matriz de inserção internacional. Essa nova matriz no âmbito da segurança "tem como característica a busca pela garantia da segurança regional na América do Sul e no Atlântico Sul". Essa busca pela segurança regional se deu paralelamente aos espaços de autonomia criados na região, que permitiram um maior protagonismo do Brasil.

Os limitantes dessa autonomia, todavia, podem ser elencados em dois pontos: i) ausência de capacidades para levar adiante os processos iniciados, deixando em segundo plano a Unasul e o CDS; ii) retomada dos Estados Unidos no sentido de securitizar a questão do narcoterrorismo na região andina e na Tríplice Fronteira, o que inviabilizaria a manutenção da autonomia brasileira.

Em relação ao primeiro ponto, é fato que houve avanços no aspecto mais sensível da integração, as questões de segurança e defesa, a despeito dos avanços anteriores em áreas comerciais e econômicas. Como ressalta Couto (2003), a integração regional permanece como uma tarefa inconclusa, sobretudo em função da concorrência com outros projetos integracionistas que os vizinhos brasileiros advogam. Nesse sentido, apesar de a integração sul-americana ser tratada como estratégica pela diplomacia brasileira, não se pode afirmar que todos os 11 países do bloco sejam estratégicos para o Brasil (COUTO, 2003, p. 196).

Destarte, é importante destacar o conceito de parceria estratégica, que, para o autor, envolve interesses ou objetivos comuns, em que as partes auferem benefícios de magnitudes semelhantes, ainda que tenham objetivos diferentes, mas não contraditórios ou concorrentes. Silva (2015, p. 163) afirma que houve um uso inconsequente do termo no discurso diplomático e "uma parceria estratégica passa a se tornar mais um título do 
que uma designação de relações bilaterais definidas pela cooperação e convergência entre as políticas e a economia de dois países" (SILVA, 2015, p. 163). Couto (2003) concorda com esse aspecto para a América do Sul ao afirmar que nem todos os países da América do Sul são estratégicos ao Brasil, mesmo que assim sejam tratados pela diplomacia.

0 problema decorrente desse aspecto é que ele demonstra que a região está calcada apenas no discurso e não na prática daquilo que seria de fato "estratégico", uma vez que não há benefícios mútuos. Exemplo desse ponto é trazido por Couto (2003) ao afirmar a existência de um descompasso entre o discurso da diplomacia brasileira e a prática da iniciativa privada. Embora o governo brasileiro reafirme a primazia da América do Sul e a necessidade de ocupação desse espaço pelas empresas nacionais, nota-se uma clara preferência dos agentes econômicos nacionais pelos mercados tradicionais - "a escala regional não tem se mostrado uma via obrigatória para a projeção global das empresas brasileiras" (COUTO, 2003, p. 201). Os maiores volumes de investimento direto externo do Brasil não se concentram na América do Sul, embora o Brasil tenha se tornado superavitário em relação a todos os seus vizinhos, excetuando-se a Bolívia (COUTO, 2003, p. 200).

Esse viés é importante, pois somente a partir de um ambiente econômico e comercial bem estabelecido, que pode ou não ser precedido de uma motivação política, será possível criar vínculos fortes no âmbito securitário, já que essa é a vertente mais sensível de qualquer processo integracionista. Portanto, a falta de coordenação e o tímido papel de liderança e de paymaster do Brasil no processo de integração regional podem ser um importante limitador para avançar a autonomia na região, principalmente quando se tem em mente que, além desses limitantes, há ainda a necessidade de manter a América do Sul como um plano de Estado e não só de governo.

Saraiva (2014, p. 32) afirma que, quanto à América do Sul, no governo da presidente Dilma Rousseff, se mantiveram as estratégias de política externa do governo Lula, de transformar a região em um espaço geopolítico. No entanto, "a vontade política demonstrada por Lula de articular visões favoráveis à construção de uma liderança regional não foi mais sustentada" e "esvaziou a dimensão política do comportamento brasileiro frente à região no que diz respeito às ações do Brasil como ator estruturador das instituições regionais e definidor de agendas" (SARAIVA, 2014, p. 32). Para a autora, 
o CDS ficou em compasso de espera, embora a Unasul tenha continuado como referência para resolver situações de crise regional.

Em relação ao segundo ponto elencado, a retomada da presença norteamericana na região, sabe-se que, apesar de ter havido o gradual deslocamento da guerra às drogas para a guerra ao terror, a América do Sul continuou nos documentos norte-americanos. Além disso, a ativação da IV Frota Naval, já mencionada, a partir dos recentes descobrimentos do pré-sal na costa brasileira, e os inúmeros recursos naturais presentes na região sempre darão à América do Sul um caráter estratégico para os Estados Unidos.

Nesse sentido, outro elemento que pode dificultar o aprofundamento é a possível tensão entre a ênfase norte-americana na segurança hemisférica e a ênfase brasileira na visão de segurança regional (SVARTMAN, 2014). A realidade da região sulamericana - e entendendo região como um grupo de Estados interdependentes que, por imperativos geográficos de proximidade ou vizinhança, compartilham ameaças e preocupações militares, independentemente de seus interesses (BUZAN, 1991) - possui demandas de segurança que lhe são próprias e que só podem ser resolvidas conjuntamente. Há, portanto, a necessidade de que o Brasil, bem como as recentes instituições criadas, possua mecanismos para neutralizar políticas unilaterais dos Estados Unidos para a região e fazer da autonomia regional a sua principal orientação.

\section{CONCLUSÃO}

0 artigo discutiu como as mudanças sistêmicas do pós-Guerra Fria, as mudanças de polos de poder e o deslocamento da agenda de guerra às drogas para guerra ao terror, bem como o pós-11 de Setembro, com o rebalanceamento dos EUA para a Ásia-Pacífico, permitiram a criação de espaços de autonomia regionais e um maior protagonismo brasileiro na América do Sul.

Aliada a isso, a vontade política dos governos de FHC e Lula denotou à região um caráter estratégico. A mudança da matriz de política externa nesse período, e o modo como a política de defesa brasileira insere-se nessa nova matriz de inserção internacional, surge sob o argumento de que a maior projeção internacional do Brasil deve vir acompanhada de uma maior capacidade de defesa e segurança. Nesse sentido, 
as iniciativas brasileiras na construção da agenda sul-americana de segurança e defesa, com a criação da Unasul e do CDS, são formas de fortalecer institucionalmente a região.

Pode-se afirmar, assim, que houve uma reestruturação das relações regionais, sob uma nova forma de integração em um espaço geográfico claramente definido e com reorientação da projeção estratégica em matéria de segurança e defesa. A Unasul permitiu o deslocamento do unilateralismo e do bilateralismo, que caracterizavam as relações entre os governos da região, para um viés multilateral.

Destacou-se, todavia, que, apesar do surgimento dessas iniciativas cooperativas, as assimetrias, sejam físicas, econômicas ou políticas entre os países da região, assumem conotações importantes nas relações regionais. Como as iniciativas tratadas são recentes e, de certa forma, não estão consolidadas, elas dependem da conjuntura doméstica e internacional e, principalmente, da continuidade da vontade política dos Estados, a partir de uma constante reafirmação.

\section{REFERÊNCIAS BIBLIOGRÁFICAS}

ALMEIDA, Paulo Roberto de. O Brasil e as relações internacionais no pós-Guerra Fria. In: LADWIG, Nilzo Ivo; COSTA, Rogério Santos da (orgs,). Vinte anos após a queda do muro de Berlim: um debate interdisciplinar. Palhoça - SC: Editora da Unisul, 2009.

BANDEIRA, Luiz Alberto Moniz. O Brasil e a América do Sul. In: OLIVEIRA, Henrique Altemani de; LESSA, Antônio Carlos. (orgs) Relações Internacionais do Brasil: Temas e agendas. São Paulo: Editora Saraiva, 2006.

BATTAGLinO, J. O Brasil e a criação do Conselho de Defesa Sul-americano. Uma convergência de vantagens. Revista Nueva Sociedad, 2009.

BUZAN, Barry. People, states and fear: an agenda for security studies in the Post-Cold War era. Londres: Wheatsheaf, 1991.

BUZAN, Barry; WAEVER, Ole. Regions and Powers: the Structure of International Security. Cambridge: Cambridge University Press, 2003.

COUTO, Leandro. Relações Brasil-América do Sul: a construção inacabada de parceria com o entorno estratégico. In: LESSA, Antônio Carlos; OLIVEIRA, Henrique Altemani de. Parcerias estratégicas do Brasil. Belo Horizonte: Fino Traço, 2013.

DECLARAÇÃO DE CUSCO. Disponível em: <http://www.comunidadandina.org/documentos/dec_int/cusco_sudamerica.htm> Acesso em: 09 nov 2015. 
DoD (Department of Defense). Western Hemisphere Defense Policy Statement. Disponível em: <http://archive.defense.gov/news/WHDPS-English.pdf> Acesso em: 10 nov 2015.

. Asia-Pacific Rebalance. Disponível em: <http://www.defense.gov/News/SpecialReports/0415_Asia-Pacific-Rebalance> Acesso em: 11 nov 2015.

FUCCILLE, Alexandre; REZENDE, Lucas Pereira. Complexo Regional de Segurança da América do Sul: Uma Nova Perspectiva. Contexto Internacional, Rio de Janeiro, vol.35, no1, janeiro/junho 2013. Disponível em: <http://contextointernacional.iri.pucrio.br/media/3artigo351.pdf> Acesso em: 12 nov 2015.

FUCCILLE, Alexandre. Conselho de Defesa Sul-Americano (CDS): balanços e perspectivas. Anais IX Encontro da ABCP. Brasília: 2014.

GRANATO, Leonardo. A autonomia como vetor da ação externa e da integração na América do Sul: postulações teóricas. Revista Oikos. Rio de Janeiro, Volume 13, n. 2, 2014.

em:

<http://www.revistaoikos.org/seer/index.php/oikos/article/viewFile/372/210> Acesso em: 22 out 2015.

IKENBERRY, G.J. Liberal Leviatham: The origins, crisis and transformation of the American World Order. Princeton University Press: Princeton, NJ, 2011.

LIMA, Maria Regina Soares de. Teses Equivocadas sobre a Ordem Mundial Pós-Guerra Fria. Dados. Rio de Janeiro, v. 39, n. 3, 1996. Disponível em: <http://www.scielo.br/scielo.php?script=sci_arttext\&pid=S0011-

$52581996000300005>$ Acesso em: 20 out 2015.

LIMA, Maria Regina Soares de; COUTINHO, Marcelo Vasconcelos. Globalização, Regionalização e América do Sul. Análise de Conjuntura OPSA, no 6, 2005. Disponível em: <http://www.plataformademocratica.org/Publicacoes/22212_Cached.pdf> Acesso em: 01 nov 2015.

MEDEIROS FILHO, Oscar. Breve panorama de segurança na América do Sul. In. O Brasil e a segurança no seu entorno estratégico: América do Sul e Atlântico Sul. Organizadores: Reginaldo Mattar Nasser, Rodrigo Fracalossi de Moraes. Brasília: Ipea, 2014, pp. 21-42.

OLIVEIRA, Henrique Altemani de; LESSA, Antônio Carlos. Relações Internacionais do Brasil: temas e agendas. V.1 São Paulo: Saraiva, 2006.

PAGLIARI, Graciela de Conti. Segurança regional e política externa brasileira: as relações entre Brasil e América do Sul, 1990-2006. Tese (Doutorado em Relações Internacionais), Programa de Pós-Graduação em Relações Internacionais, Universidade de Brasília, 2009.

PECEQUILO, Cristina Soreanu. A Política Externa do Brasil no Século XXI: Os Eixos Combinados de Cooperação Horizontal e Vertical. Revista Brasileira de Política Internacional, v. 51 (2): p. 136-1532008. 
PINHEIRO, Letícia. Traídos pelo desejo: um ensaio sobre a teoria e prática da política externa brasileira. Revista Contexto Internacional, vol. 22, n. 2, p. 305-335, 2000.

RUSSELL, Roberto; TOKATLIAN, Juan Gabriel. De la autonomía antagónica a la autonomía relacional: una mirada teórica desde el Cono Sur. Perfiles Latinoamericanos, no. 21, diciembre, pp. 159-194, 2003.

SANTOS, Luís Cláudio Villafañe. A América do Sul no discurso diplomático brasileiro. Brasília: FUNAG, 2014.

SARAIVA. Miriam Gomes. Balanço da política externa de Dilma Rousseff: perspectivas futuras? Relações Internacionais, Lisboa, n. 44, dez. 2014.

SILVA, André Luiz Reis da. Geometria variável e parcerias estratégicas: a diplomacia multidimensional do governo Lula (2003-2010). Contexto Internacional, 37(1), 143-184, 2015.

. Segurança e desenvolvimento na projeção internacional do Brasil (2003-2013). In: ARTURI, Carlos Schmidt (Org.). Políticas de Defesa, Inteligência e Segurança. Editora UFRGS, Porto Alegre, 2014.

SOUZA, André de Mello e; MORAES, Rodrigo Fracalossi de. A relevância do terrorismo na política internacional contemporânea e suas implicações para o Brasil. In: SOUZA, André de Mello e; NASSER, Reginaldo Mattar; MORAES, Rodrigo Fracalossi de (Orgs.). Do 11 de setembro de 2001 à Guerra ao Terror: reflexões sobre o terrorismo no século XXI. Brasília: Ipea, 2014.

SVARTMAN, Eduardo. A agenda de defesa do Brasil para a América do Sul. In: ARTURI, Carlos Schmidt (Org.). Políticas de Defesa, Inteligência e Segurança. Editora UFRGS, Porto Alegre, 2014.

TANNO, G. A Contribuição da Escola de Copenhague aos Estudos de Segurança Internacional. Contexto Internacional, Rio de Janeiro, v. 25, n.1, p. 47-80, 2003. Disponível em: <http://www.scielo.br/pdf/cint/v25n1/v25n1a02.pdf>. Acesso em: 14 nov. 2015.

UNASUL. Objetivos específicos. Disponível em <http://www.unasursg.org/es/objetivosespecificos> Acesso em:22 nov 2015.

VILLA, Rafael Antônio Duarte; VIANA, Manuela Trindade. Security issues during Lula's administration: from the reactive to the assertive approach. Revista Brasileira de Política Internacional, Brasília, v. 53, p. 91-114, Dec. 2010. Disponível em: <http://www.scielo.br/scielo.php?script=sci_arttext\&pid=S0034-

$73292010000300006>$ Acesso em: 20 nov. 2015. 